\title{
Words within Words: Layout Strategies in Some Glossed Manuscripts of the Iliad
}

After centuries of printed books, we moderns have become used to printed pages where the visual organization of space clearly subordinates notes to text by using a smaller type size and confining them to the lower part of the textblock. We might find it strange at first that medieval scribes never discovered the convenience of footnotes. ${ }^{1}$ In manuscripts the various possible forms of what we could term 'accessory texts' do not occupy a single standard position: occasional annotations, sporadic glosses, or systematic commentaries are situated in different parts of the page according to a plurality of arrangements.

The popularity of specific solutions varied according to the period, the context, and the content of the works; the same solutions can be found in chronologically or spatially distant texts, as well as different solutions in different versions of the same text. ${ }^{2}$

Among the various types of association between text and commentary, glossing, or notes, the simplest case is that of continuous commentaries written on a roll or in a codex separate from the reference text; in all other cases text and commentary are found in the same book, resulting in a number of different layouts. Here is a summary list of the most widespread combinations:

- codices with commentaries entirely written after the main text (reproducing or not reproducing its layout)

First published as Maniaci, Marilena (2006), 'Words within Words: Layout Strategies in some Glossed Manuscripts of the Iliad', in Manuscripta, 50, 2: 241-268.

This paper reproduces, with slight variations and revisions, the text of a talk given at the ThirtySecond Annual Saint Louis Conference on Manuscript Studies (14-15 October 2005) at Saint Louis University in a session on codicology sponsored by The Bibliographical Society of America. I am very grateful to Gregory Pass, the organizer of this session, for having invited me to participate and for offering the opportunity to publish my contribution in this journal.

1 See Grafton 1997.

2 For an updated bibliography on the layout of commentaries in manuscript books, see Maniaci 2006. The references given in the following footnotes will therefore be limited to a bare minimum. 
- codices with more or less extensive portions of text and commentary alternating within the written area (laid out full page or in two columns)

- codices with text and commentary closely interwoven within the written area in juxtaposing blocks of various size and form, creating a sort of 'check pattern'

- codices with commentary written in between the lines of the main text

- codices with commentary written in columns positioned to the right or (less commonly) the left or on both sides of the main text, in which case the commentary can be either within the boundaries of the written area or in the margins

- codices with full page or two-column layouts where the commentary forms an open or closed frame (or alternatively two half-frames), taking up part or all of the margins.

The reality of manuscripts is, as always, much more varied and unpredictable. It is further complicated by the stratification through time of annotations belonging to different hands, periods, contexts, and purposes that had to be fitted within whatever space was left on the page. In fact, recent research has suggested the limited use of a purely formal study of manuscript layout ${ }^{3}$ and highlighted the greater interest of an in-depth analysis of the various ways in which scribes synchronized texts and glosses and were able to address the difficulties encountered in their work.

In this regard, it is evident that some methods of linking text and commentary were more problematic for scribes than others and are, therefore, of greater interest to codicologists. Two formats stand out at first glance for their complexity: the 'check' layout and the 'frame' layout. The difference between the two layouts is not solely visual; in fact, they entail two quite different working methods. The 'open' form of the check layout sets (almost) no limit to the extent of text and commentary to be copied on a single page, but requires the scribe meticulously to copy both of them together-page by page and block by block. The check layout, however, makes it easy for the scribe to supplement the commentary with additional material by extending at will the number and length of the glosses contained on each page. Alternatively, the frame layout is a 'closed' form; it isolates the commentary from the text, limiting it to marginal spaces that, while varying to some extent in size from one codex to the other, remain in any case predetermined and cannot be adapted to the needs of the moment. The 'exegetic capacity' of the frame layout is therefore limited to the capacity of the margins.

3 As proposed by Powitz 2005. 
On the positive side, however, the frame layout allows scribes the freedom of deciding whether to transcribe the commentary along with the main text or in a separate stage. In short, both forms have specific advantages and disadvantages, the results of which can be shown only through an in-depth analysis of individual pages.

\section{Commented Homeric codices}

In Byzantine book production we have evidence of the (probably widespread) use of frame layout for majuscule codices from late Antiquity. ${ }^{4}$ Frame layout was also widely adopted in minuscule codices from the $9^{\text {th }}$ to the $12^{\text {th }}$ century, after which it virtually disappeared, giving way to simpler layouts. The reason for the decline of the frame layout lies probably in the decreasing size of codices from the end of the Comnenian age, which 244 made the smaller margins unsuited to large quantities of text. ${ }^{5}$ The frame layout was particularly used in the so-called catena (chain) of scriptural texts, a specific form of exegesis based on the linking of excerpts from the Fathers and early ecclesiastical writers. ${ }^{6}$ However, it was already common early on in the commentaries of profane texts, both in prose and poetry. The annotations in the margins of classical Greek texts, however, are usually too few and discontinuous to be considered a running commentary, or they appear only in the first pages of the codex. ${ }^{7}$ In most cases, the tradition of such commentaries does not demonstrate sufficient stability and is often attested by a single witness.

Commentaries on Homer, especially the Iliad, represent a significant exception, both for the quantity of surviving witnesses and for the relative stability of the commentary (for extent and content). Especially rich is the tradition of the socalled scholia vetera of the Iliad, consisting of 25 manuscripts (to which must be added the fragments attested in papyri), which has been documented in a

4 Basic updated bibliography on the relation of text and commentary in Greek papyri and late Antique codices can be found in Messeri / Pintaudi 2002.

5 On the dimensions and layout of Byzantine parchment codices, see Maniaci 2002a.

6 Despite intensive research, the history of the catena does not seem to be fully explained, both from the textual and codicological point of view. Dorival 1986, makes an interesting effort to take both aspects in account, but his conclusions require careful evaluation.

7 As it happens in Arethas's copy of Aristotle: Vatican City, Biblioteca Apostolica Vaticana, Cod. Urb. gr. 35; see Follieri 1969, pl. 18. 
monumental and extremely accurate edition by Hartmut Erbse. ${ }^{8}$ Though this is not the appropriate context to discuss the complex details of the composition of Homeric scholia, a glance at the stemma (Fig. 1) is enough to observe that four of the five oldest codices, all written between the middle of the $11^{\text {th }}$ and the beginning of the $12^{\text {th }}$ century, ${ }^{9}$ are part of a same family (bT).

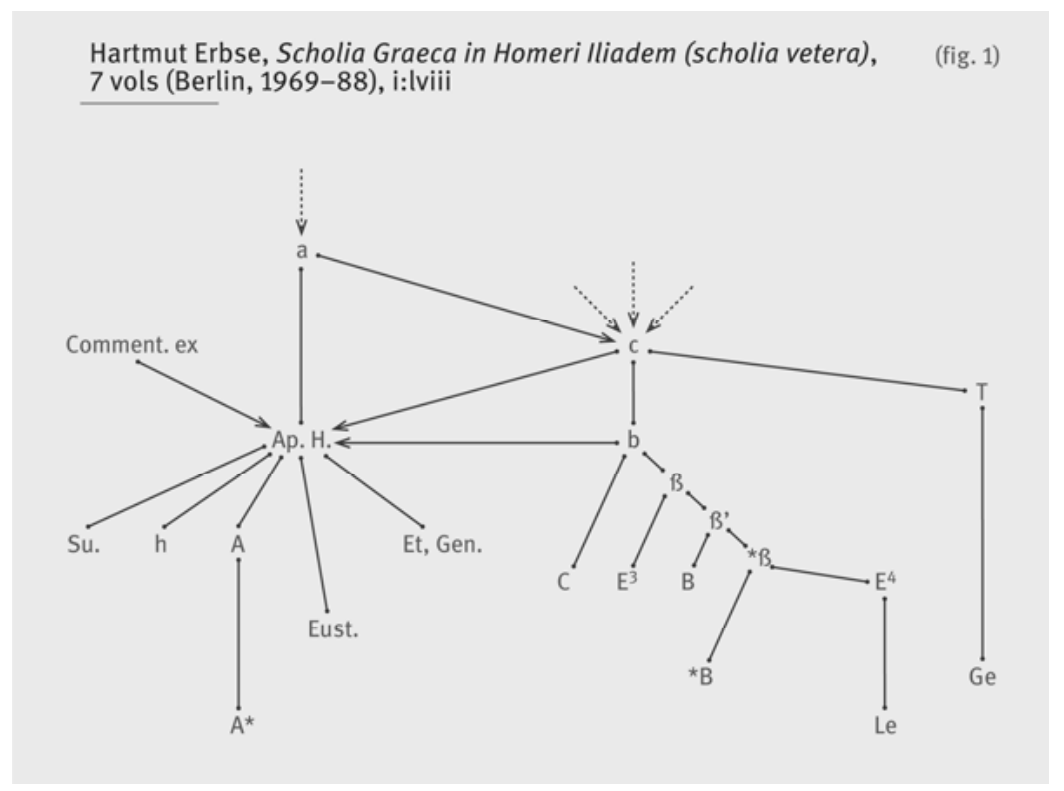

Fig. 1: Hartmut Erbse, Scholia Graeca in Homeri Iliadem (scholia vetera), 7 vols (Berlin, 196988), i:lviii

These manuscripts are: Venice, Biblioteca Marciana, Cod. Marc. gr. 453 (B) (Fig. 2); El Escorial, Real Monasterio de San Lorenzo, Cod. U.I.1 (E³) (Fig. 3); London, British Library, Burney 86 (T) (Fig. 4); and Florence, Biblioteca Medicea Laurenziana, Cod. Plut. 32.3 (C) (Fig. 5). A fifth and older Venetian codex, Marc. gr. 454 (A) (Fig. 6), ascribable on a palaeographical basis to the middle of the $10^{\text {th }}$ century, is the unique direct Byzantine witness of a different branch of the

8 Erbse 1969-88.

9 London, British Library, Burney 86 is the only manuscript of the group to be more precisely datable according to a partially illegible colophon on fol. 281V referring to 1014 or (rather) 1059. 
tradition of the scholia vetera. ${ }^{10}$ All five codices are characterized by a frame layout (with the commentary distributed on three or four margins) and are all, predictably, of medium large or very large size, a format never again attested in the tradition of Homeric commentaries (Tab. 1). Each of these five manuscripts is by a different scribe, responsible for both the main text and the bulk of the commentary, to which must be added, of course, the stratifications of later annotations. The two mid-11 ${ }^{\text {th }}$-century witnesses in the Venice and El Escorial manuscripts (B and $\mathrm{E}^{3}$ ) are so similar from both the physical and textual point of view that they can be referred to as 'twins'."11

All scribes clearly strived for legibility, doing their best to adhere to the basic criterion of keeping all glosses within the boundaries of the page to which they refer without straying onto the next. While they all share this main criterion and the choice of page-layout, the five scribes-including the 'twins'-differ both in terms of certain general formatting choices and of certain expedients adopted to address specific problems in the 'management of the page'. Some differences are already evident when we visually compare the codices, while others require a more indepth analysis. Because of all these features, commented codices of the Iliad represent an ideal example for illustrating the potential of a systematic approach to the study of the frame layout.

Dimensions of the five oldest Iliad codices with frame layout (in mm)

(tab. 1)

\begin{tabular}{|c|c|c|c|c|c|c|c|}
\hline Incunabula & Sigla & Century & H & $\underline{\mathbf{L}}$ & $\mathrm{H}+\mathrm{L}$ & Folios & Lines of text \\
\hline |Venice, Marc. gr. 454 (822) & ${ }_{1}^{A}$ & $1^{10^{\text {th }}}$ & 393 & 278 & | 671 & 327 & $1^{25}$ \\
\hline |Venice, Marc. gr. 453 (821) & $\left.\right|^{B}$ & $1^{11^{\text {th }}}$ & 1405 & 315 & , 720 & 338 & $12,20-27(20-24)$ \\
\hline |El Escorial, gr. 291 (Y.I.i) & $\mathrm{I}^{3}$ & $\left.\right|^{11^{\text {th }}}$ & 360 & 284 & 644 & 328 & |20-27 (20-24) \\
\hline |London, Burney 86 & $1^{T}$ & $1^{11^{\text {th }}}$ (prob. 1059) & ) 305 & 240 & 1545 & 281 & 27-29 \\
\hline |Florence, Laur. Plut. 32.3 & ${ }_{1} \mathrm{C}$ & $1^{11^{\text {th }} / 12^{\text {th }}}$ & 297 & 244 & |541 & |424 & $15,20,25$ \\
\hline
\end{tabular}

Tab. 1: Dimensions of the five oldest Iliad codices with frame layout (in $\mathrm{mm}$ )

10 See the complete facsimile with an introduction by Comparetti 1901.

11 For a detailed description, pointing out the similarities between the two codices, see Maniaci 2006. 


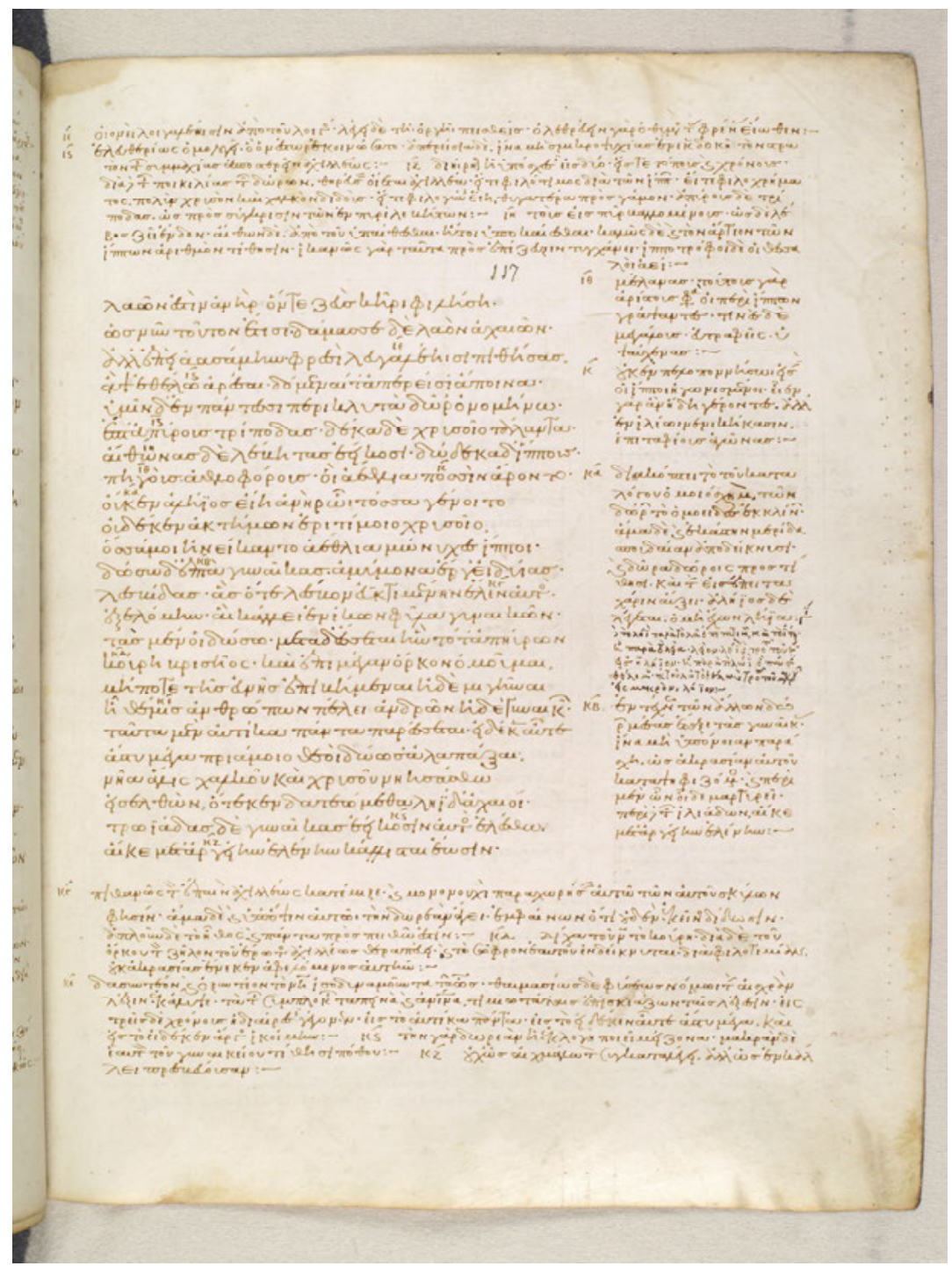

Fig. 2: Venice, Biblioteca Marciana, Cod. Marc. gr. 453 (B), f. 117r. With permission of the Biblioteca Marciana 


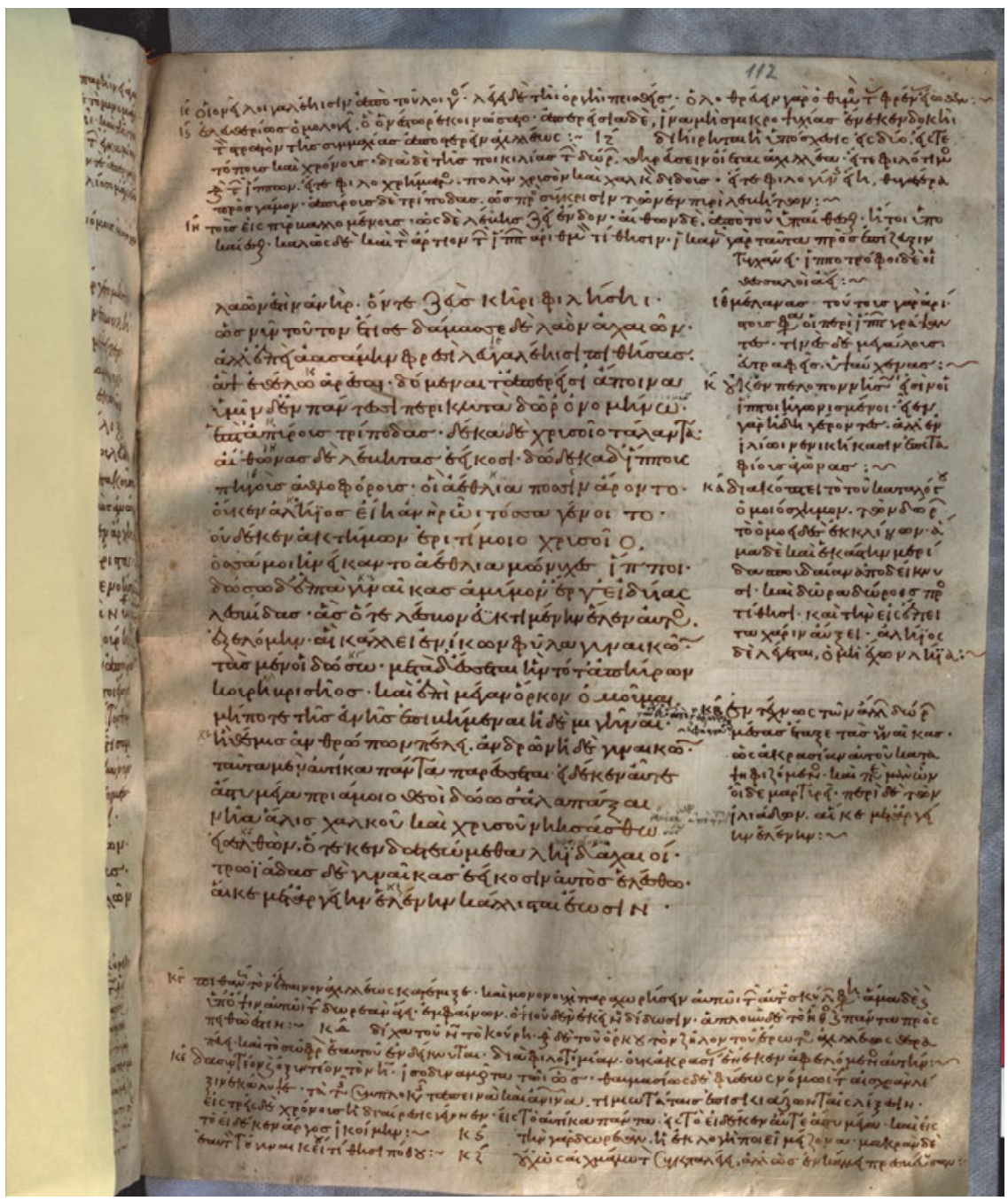

Fig. 3: El Escorial, Biblioteca del Real Monasterio di San Lorenzo, Cod. u.I.1 (E³), f. 112r. With permission of the Biblioteca del Real Monasterio di San Lorenzo 


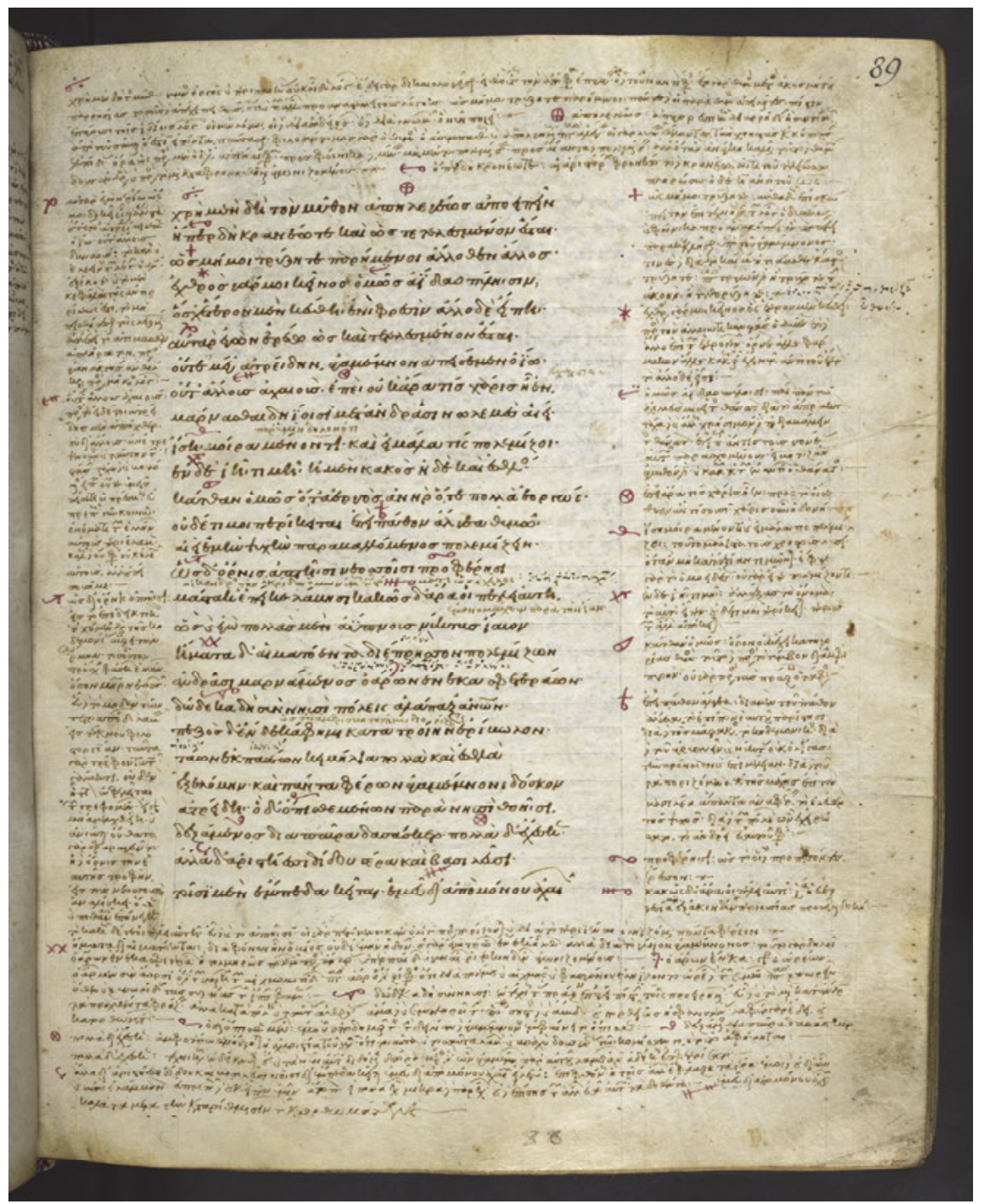

Fig. 4: London, British Library, Burney 86 (T), f. 89r. (C) The British Library Board 


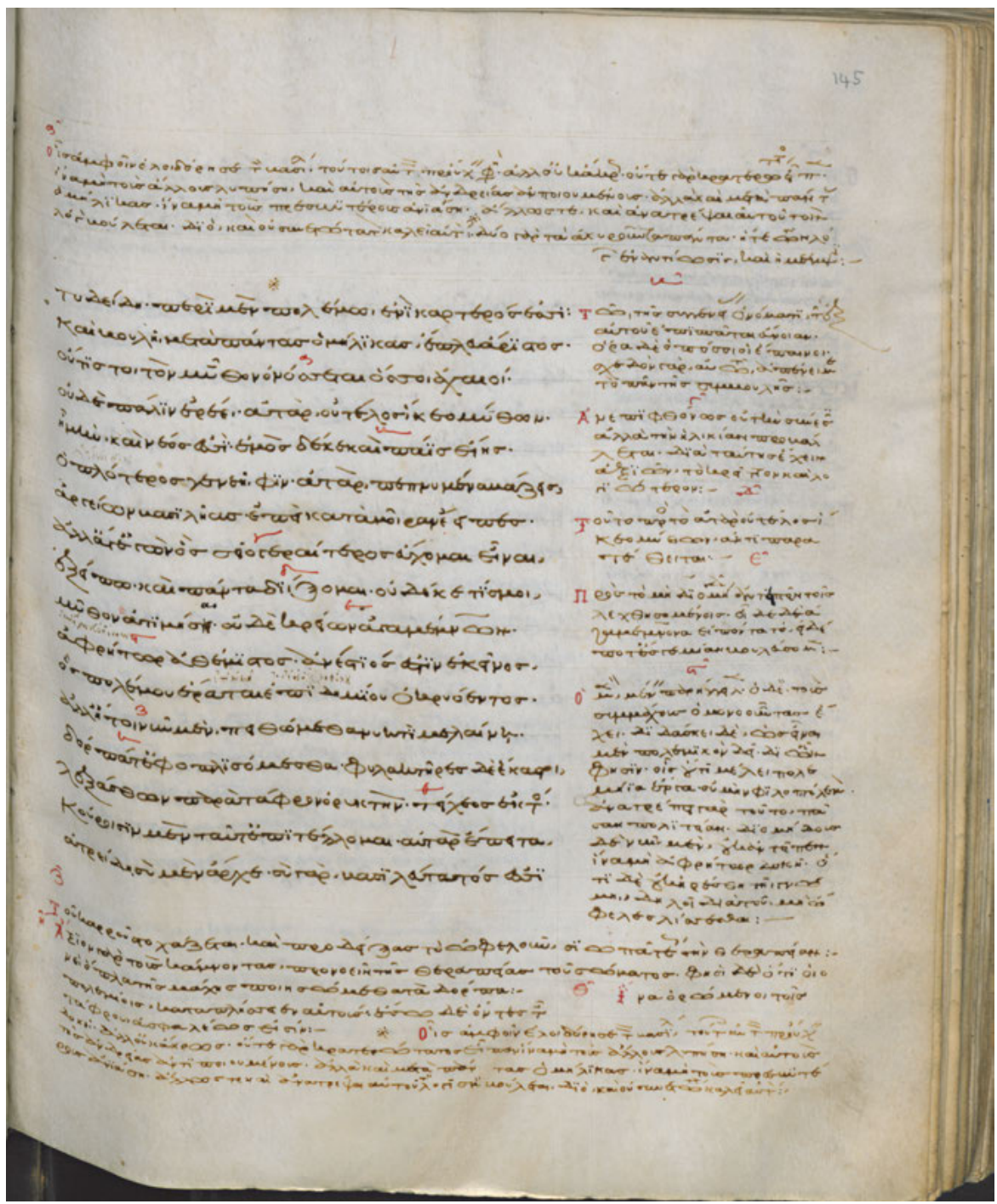

Fig. 5: Florence, Biblioteca Medicea Laurenziana, Cod. Plut. 32, 3 (C), f. 145r. With permission of the Ministero della Cultura (MiC) 


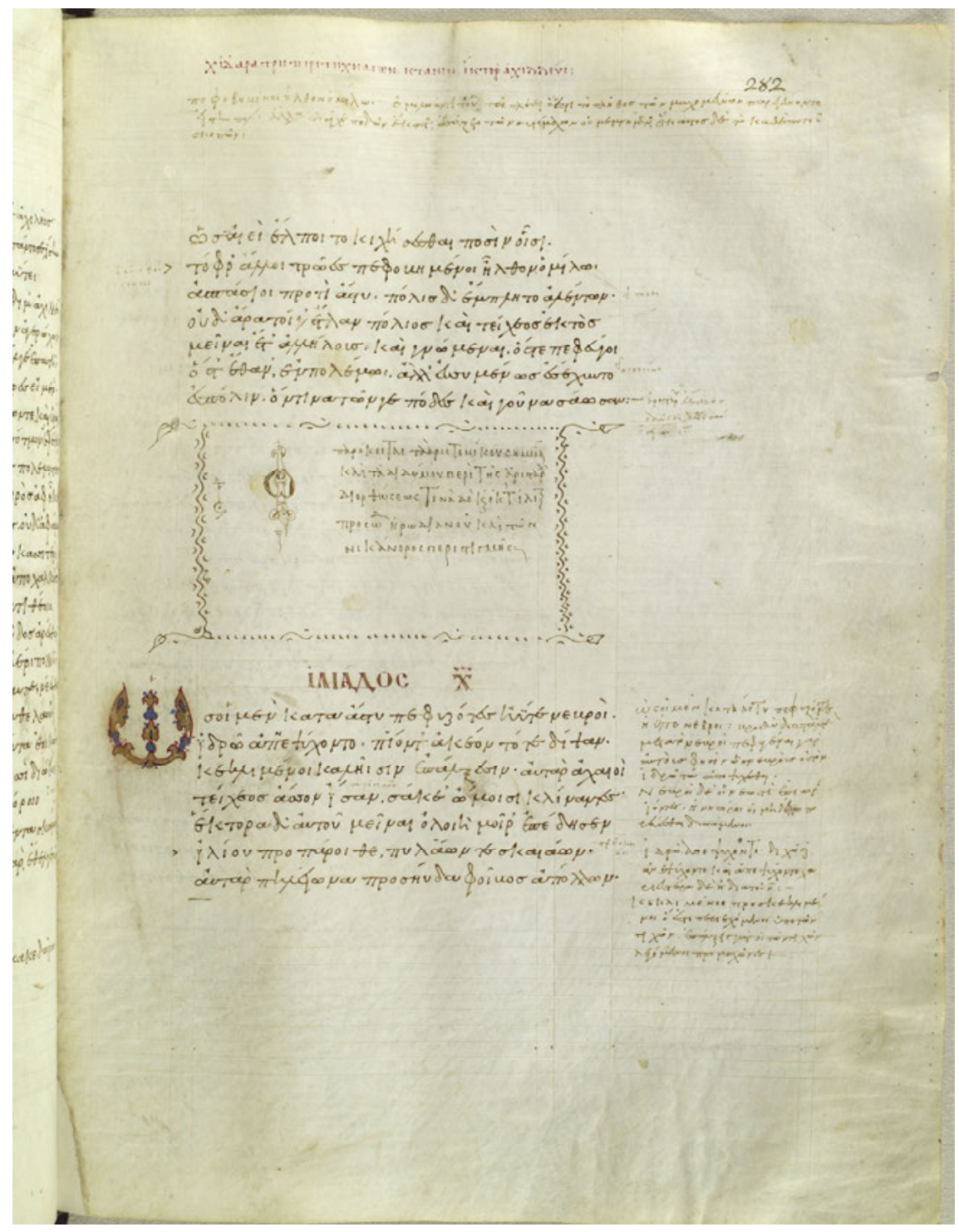

Fig. 6: Venice, Biblioteca Marciana, Cod. Marc gr. 454 (A), f. 282r. With permission of the Biblioteca Marciana 


\section{Methodological considerations}

As I have already argued elsewhere, ${ }^{12}$ when copying commented manuscripts, scribes must address two basic requirements:

- $\quad$ synchronizing text and commentary on each page (or on two facing pages) without, if possible, straying onto the next (especially in the case of recto and verso) and without inserting scholia too far away from the passages to which they refer, thus hindering legibility

- adequately linking each scholium to relevant passages, helping the eye go from one to the other

With regard to the first requirement, obviously the difficulty of synchronization is to some extent proportional to the ratio between the length of the main text and the length of the commentary: as the size of the commentary increases, so does the risk of difficulty in linking it to the main text. However, since the space occupied by a given sequence of words can be decreased by resorting to abbreviations or letter superpositioning, the actual size of the commentary will not be directly determined by the number of words or the characters to which they would normally correspond, but by the number of characters actually positioned on the written line. In any case, the total size of the commentary is not the only variable that may pose problems to the scribe. Total size being equal, a commentary consisting of many brief scholia will pose different problems from a commentary consisting of a few long ones: when the two typologies coexist in the same commentary (as often happens), it is the way in which they alternate that determines the level of difficulty (in unfortunately unpredictable ways). In general, the greatest factor in determining the difficulty of the scribe's work is the relation between the length of individual scholia and their frequency. A series of brief scholia referring to lines of the main text sufficiently distant from one another will not pose a problem. But the longer the scholia and the closer the lines to which they refer, the more the scribe's ability will be put to the test, the greatest difficulty occurring when a number of long scholia refer to the same line. To evaluate these difficulties it is necessary to consider: a) the position of each scholium on the page and $b$ ) the position of commented passages/lines.

In regard to the second requirement (that is, the association between text and commentary), the scribe must choose, in the first place, the way in which

12 Maniaci 2002b. 
text and commentary will be 'linked.' In modern printed texts, linkage is achieved through numbers positioned in the spaces between the lines of the main text and at the beginning of each note, in a rigidly ordered sequence that can either continue throughout the entire text or resume its cyclical pattern after each chapter, section, single page, or pair of facing pages. This device is, indeed, also found in medieval manuscripts (Fig. 7), but along with it there are many other linking systems, such as what I would term a 'symbolic system' consisting of small, more-or-less elaborate drawings (Fig. 8), or a 'verbal system' based on the repetition of the first words of the commented text at the beginning of the note (Fig. 9). Furthermore, different systems could be used together in the same book (Fig. 10). It is not irrelevant, as will be shown, that all these modalities of linkage are attested in Homeric commentaries.

Independently of the linking system adopted, the reading of a commented text is influenced by the relative position of text and glosses, more specifically by the position of glosses in margin A, B, and C (and possibly D) and by the distance between each gloss and the lines of text to which it refers. In this case, too, the choices, the uncertainties, or the mistakes made by the scribe can have a considerable impact on legibility, though it remains difficult to gauge precisely.

For the evaluation of the above aspects (synchronization and linking) to be as accurate as possible, it is necessary to perform for each page a quantitative analysis based on a fairly complex series of measurements, whose detailed description and interpretation I have discussed elsewhere. ${ }^{13}$ In this present article, I will limit myself to presenting a few examples of how quantitative analysis can be used to gauge the difficulties faced by the scribes, to demonstrate their choices, and to evaluate the reasons for and effectiveness of those choices.

13 See Maniaci 2006. 


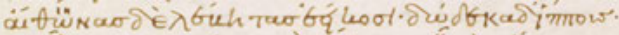

"thỉं

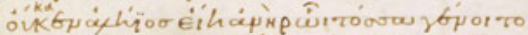

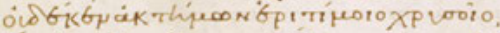

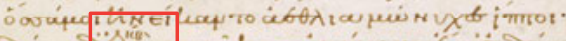

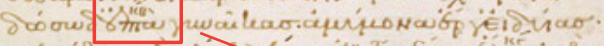

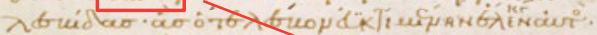

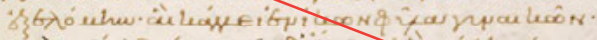

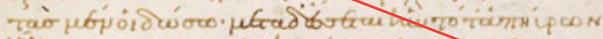

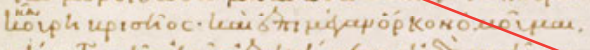

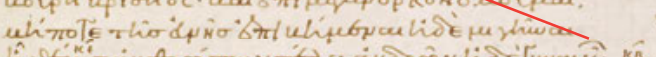

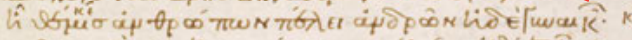

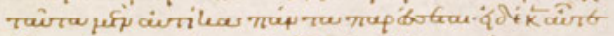

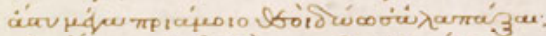

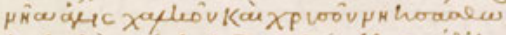

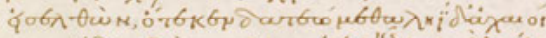

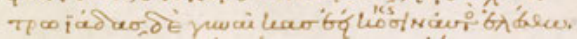

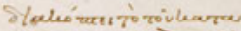

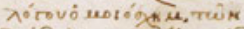

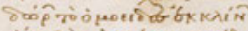

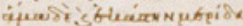

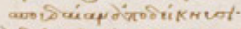

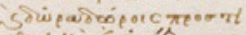

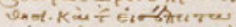

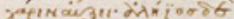
तै

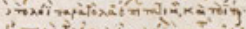

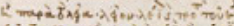

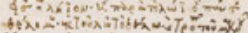
$4 c$ mance in, $\lambda$ í ies:-

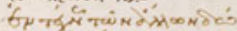

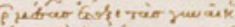

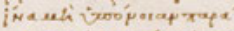
h. iv alupariap cirro

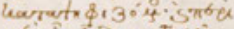

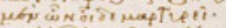
rtaij Fi $i \lambda$ a swow, äke

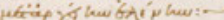

Fig. 7: Linkage of text and scholia by 'numerical system'. Venice, Biblioteca Marciana, Cod. Marc. gr. 453 (B), f. 117r. With permission of the Biblioteca Marciana

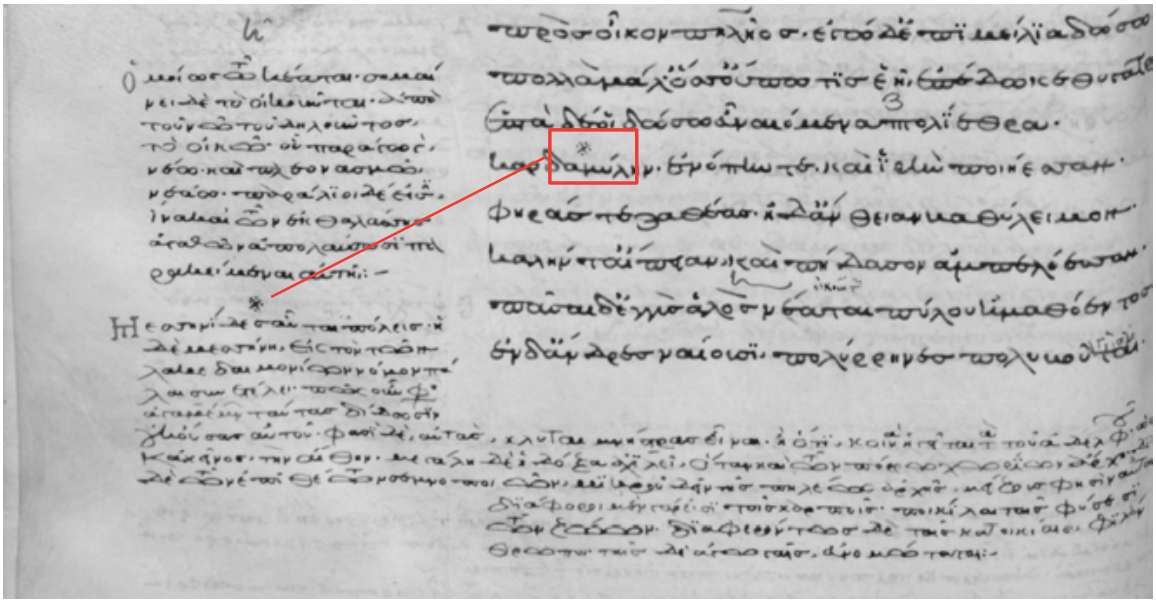

Fig. 8: Linkage of text and scholia by ‘symbolic system’. Florence, Biblioteca Medicea Laurenziana, Cod. Plut. 32, 3 (C). With permission of the Ministero della Cultura (MiC) 


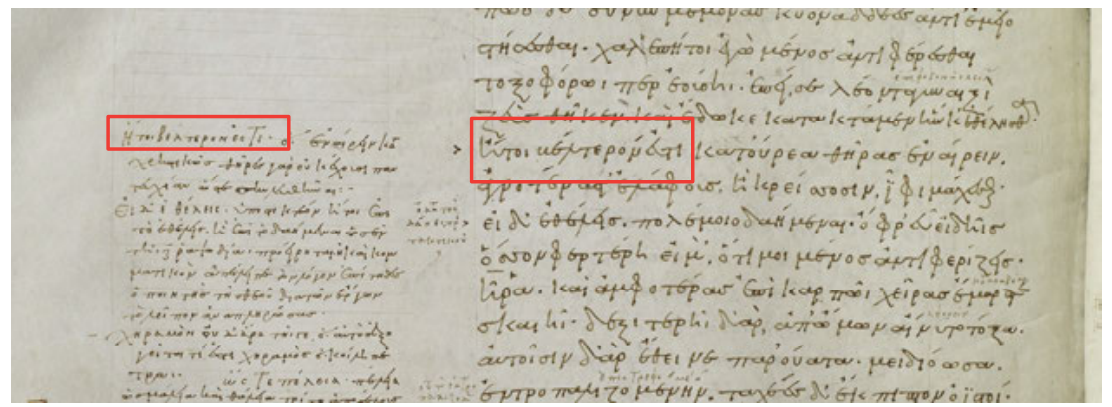

Fig. 9: Linkage of text and scholia by 'verbal system' (through lemmas or headwords). Venice, Biblioteca Marciana, Cod. Marc. gr. 454 (A), f. 279v. With permission of the Biblioteca Marciana

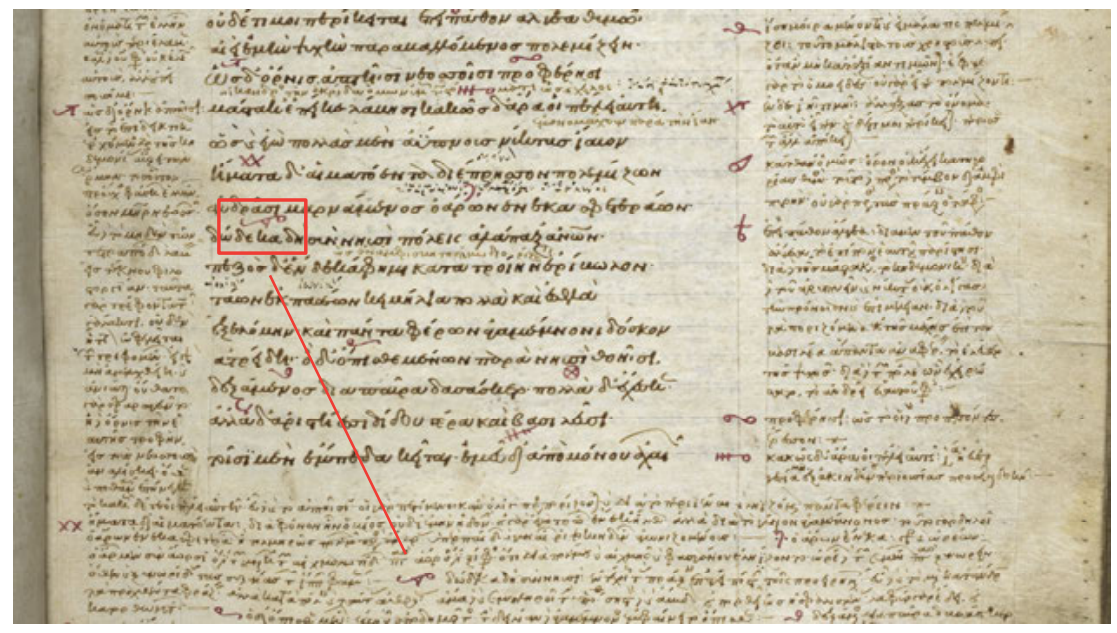

Fig. 10: Linkage cumulating two different systems (lemma + symbol.). London, British Library, Burney 86 (T), f. 89r, detail @ The British Library Board

\section{Codices $B, E^{3}, C$, and $T$ : general features}

In all four codices we are dealing with (B, $\mathrm{E}^{3}, \mathrm{C}$, and $\mathrm{T}$, as well as Venetus $\mathrm{A}$, for that matter), scholia are found in three of the four margins (upper, outer, and lower); only in Londinensis $\mathrm{T}$ are annotations also present at times in the inner 
margin and between the lines. ${ }^{14}$ While the four codices belong to the same exegetic tradition, the total quantity of commentary varies significantly: it is greatest in Londinensis $\mathrm{T}$ and least in Laurentianus $\mathrm{C}$, which contains slightly over half the amount of commentary found in $\mathrm{T}$.

Notwithstanding these differences, the quantitative distribution of the commentary throughout the poem follows similar patterns in the four manuscripts. In all four there is considerable variation from one book of the Iliad to the next, as is shown by the detailed calculations based on B and $\mathrm{E}^{3}$ (Tab. 2). The 'density' of the commentary decreases from the beginning to the end of the poem, ${ }^{15} \mathrm{a}$ feature common also in other texts, especially when targeted at a school audience. The four codices also present a second and more unusual peculiarity: a sudden leap in density of commentary, followed by a period of decline, and then a sharp increase between books $\mathrm{M}$ and N, exactly half-way through the work. This peculiarity is accompanied in all four codices by a codicological caesura ${ }^{16}$ at the end of book M, evidently meant to indicate the possibility of subdividing the work into two volumes. It was common, in fact, to comment more (and therefore to read more) upon the first books of both volumes and upon the first volume more than the second.

What then are the principles that govern the arrangement of exegetic scholia in the margins? A quick comparison of the size of the four codices allows us to grasp immediately the different working conditions of the respective scribes (Tab. 1). The two 'twin' codices are decidedly large for the Byzantine tradition and almost always have a fixed number of 24 lines per page. The other two witnesses are much smaller and marked by contrasting choices in regard to the number of lines: codex $\mathrm{T}$ has a high average of about $27-28$ lines per page, while $C$ opts for a much less cramped average of $17-18$ lines per page.

14 All the remarks concerning London, British Library, Burney 86 (not considered in Maniaci 2006 depend on a recent analysis based on the microfilm and will be further developed and refined through direct study of the manuscript.

15 Book 1 (A) has been left out of consideration because its text is acephalous in $\mathrm{E}^{3}$.

16 What I have elsewhere called a 'snodo'; see Maniaci 2000, 54. 
Quantitative distribution of the commentary throughout the Iliad $\left(\mathrm{B}\right.$ and $\left.\mathrm{E}^{3}\right)$

(tab. 2)

\begin{tabular}{|c|c|c|c|c|c|c|c|}
\hline \multirow[t]{2}{*}{ Book } & \multirow[t]{2}{*}{ Pages } & \multicolumn{2}{|c|}{ Lines of scholia } & \multicolumn{2}{|c|}{ Number of scholia } & \multicolumn{2}{|c|}{ Average length (signs) } \\
\hline & & 1st half & 2nd half & 1st half & 2nd half & 1st half & 2nd half \\
\hline B & $1^{42}$ & |494 & $\left.\right|^{287}$ & $\left.\right|^{274}$ & |172 & |40.81 & 33.75 \\
\hline$\Gamma$ & $1^{20}$ & 199 & |180 & |112 & 113 & 18.25 & 17.79 \\
\hline$\Delta$ & $1^{22}$ & |250 & 208 & |147 & |119 & |18.83 & |19.20 \\
\hline$E$ & $1^{31}$ & |281 & 232 & |160 & |140 & |27.63 & |24.70 \\
\hline$Z$ & $1^{21}$ & 196 & 193 & 116 & 118 & |17.02 & 16.56 \\
\hline$H$ & $1^{20}$ & 203 & 135 & |110 & 83 & |18.54 & 17.26 \\
\hline$\theta$ & $1^{24}$ & |266 & 156 & |129 & 84 & |23.48 & |20.23 \\
\hline I & $1^{29}$ & $1^{341}$ & |306 & 155 & |153 & |31.52 & |28.05 \\
\hline$K$ & $1^{24}$ & $1^{209}$ & $\left.\right|^{179}$ & 98 & |112 & |38.76 & 19.77 \\
\hline$\Lambda$ & $1^{33}$ & |275 & 259 & 144 & |136 & 130.54 & |30.74 \\
\hline$M$ & 19 & |135 & $\left.\right|^{116}$ & 16 & 76 & |15.65 & 13.90 \\
\hline$N$ & 135 & 1304 & 268 & 175 & |160 & |29.80 & |28.76 \\
\hline$\equiv$ & $1^{22}$ & $1^{233}$ & $\left.\right|^{191}$ & |134 & 100 & 19.65 & |21.81 \\
\hline 0 & $1^{31}$ & $\left.\right|^{278}$ & $1^{246}$ & $\left.\right|^{162}$ & |125 & |26.47 & |30.51 \\
\hline$\pi$ & $1^{32}$ & |354 & $\left.\right|^{183}$ & |172 & |111 & $\left.\right|^{32.59}$ & |25.99 \\
\hline$P$ & $1^{31}$ & $1^{220}$ & $\left.\right|^{183}$ & 109 & |91 & |30.84 & |32.61 \\
\hline$\Sigma$ & $\left.\right|^{21}$ & |161 & 200 & |78 & |117 & 20.20 & 17.75 \\
\hline$T$ & |17 & 155 & $\left.\right|^{127}$ & 94 & 66 & |13.04 & |14.68 \\
\hline$Y$ & $1^{20}$ & |176 & 134 & 85 & 12 & |21.03 & 19.10 \\
\hline$\Phi$ & 25 & |225 & |182 & |117 & |127 & |23.57 & | 17.11 \\
\hline$x$ & $1^{21}$ & $\left.\right|^{210}$ & | 160 & |124 & |102 & | 16.76 & |15.36 \\
\hline$\Psi$ & | 37 & $1^{229}$ & $1^{215}$ & |170 & |158 & |24.25 & |24.73 \\
\hline$\Omega$ & $1^{27}$ & $\left.\right|^{217}$ & $\left.\right|^{125}$ & |154 & 99 & |17.38 & | 16.61 \\
\hline Total & & |5611 & 14465 & 3095 & 2634 & 556.61 & |506.97 \\
\hline
\end{tabular}

Tab. 2: Quantitative distribution of the commentary throughout the lliad ( $\mathrm{B}$ and $\mathrm{E}^{3}$ )

To this we might add that all four scribes tend, though with some flexibility, toward what I have elsewhere defined as a 'fixed balance' page layout: that is, the number of text lines per page remains more or less the same and only the number of lines of commentary in the three (or four) margins vary. The 'fixed balance' offers some 
advantages: it simplifies the preparation of the page and makes it easy to copy text and commentary separately if needed (because the amount of text to be copied on each page is fixed independently of the size of the commentary). However, as we shall see, the 'fixed balance' layout can also lead the scribe into trouble when the commentary is too dense or distributed in an excessively irregular fashion. A more sophisticated alternative (not adopted for the copying of Homeric scholia) is that of varying the number of lines of text per page according to the size of the commentary. This system avoids the pitfalls above, but requires very careful planning of the layout and ad hoc page ruling.

\section{Page layout}

In order to produce a more detailed analysis of the page layout of $\mathrm{B}, \mathrm{E}^{3}, \mathrm{C}$, and $\mathrm{T}, \mathrm{I}$ have focused on book IX (I) where the mass of commentary is at its highest, severely testing the ability of the scribes. As shown in the graph (Chart 1), in all four codices (B and $\mathrm{E}^{3}$ are in fact identical) the size of the commentary gradually decreases throughout the entire book following a similar pattern. Particularly noteworthy is the complete absence of commentary on lines 263-299.

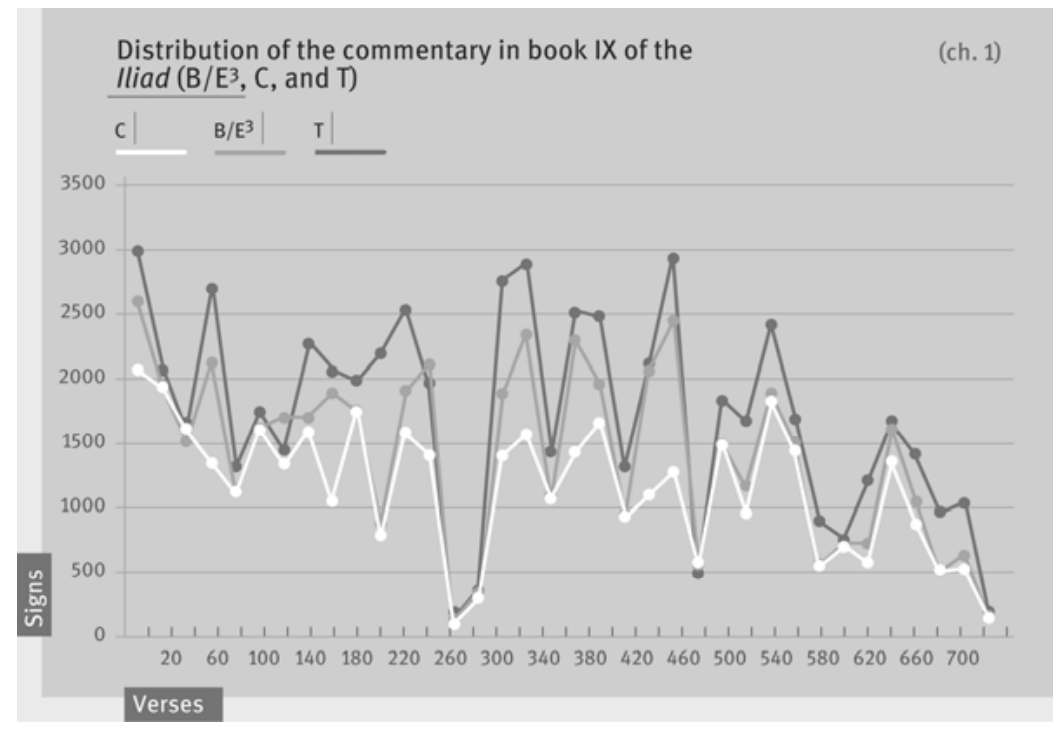

Chart 1: Distribution of the commentary in book IX of the lliad $\left(B / E^{3}, C\right.$, and $\left.T\right)$ 
This anomaly, which is common to the entire tradition, probably dates back at least to subarchetype ' $b$ ' and could be the result of the loss of a leaf containing lines 263299 (18 per page), which led to the missing lines being reinserted without commentary from another source.

If we consider (using the Erbse edition) the number of scholia in each codex, we note that T contains 91\% of the total known corpus of exegetic scholia, twins $\mathrm{B}$ and $\mathrm{E}^{3}$ contain $66 \%$, and $\mathrm{C}$ contains $62 \%$. The gap between the codices further increases when, instead of the sheer number of scholia, we consider their actual size, that is the number of graphic signs in the commentary: T holds $95 \%$ of the total, $\mathrm{B}$ and $\mathrm{E}^{3} 72 \%$, and C 58\% (Tab. 4). This is due to the fact that many scholia common to all four codices are found in a more extended version in $\mathrm{T}$, whereas they are often mutilated in $\mathrm{C}$. Furthermore, the scribe of $\mathrm{C}$ omits, as we shall see, a number of scholia, significantly chosen among the longer ones. Thus, in terms of the sheer mass of graphic signs the commentary in $\mathrm{T}$ is $25 \%$ more than that of $\mathrm{B} / \mathrm{E}^{3}$ and about $40 \%$ more than $\mathrm{C}$.

\begin{tabular}{|c|c|c|c|}
\hline \multicolumn{3}{|c|}{$\begin{array}{l}\text { Distribution of the commentary in book IX of } \\
\text { the lliad }\left(\mathrm{B} / \mathrm{E}^{3}, \mathrm{C} \text {, and } \mathrm{T}\right)\end{array}$} & \multirow{2}{*}{$\begin{array}{l}\text { (tab. 3.1) } \\
\text { Codex C }\end{array}$} \\
\hline Verses & Codex T & Codices B/E & \\
\hline |1-20 & |2969 & |2590 & |2064 \\
\hline |21-40 & |2062 & 1946 & 1946 \\
\hline , 41-60 & |1619 & |1504 & |1612 \\
\hline , 61-80 & |2695 & $\left.\right|^{2113}$ & |1346 \\
\hline |81-100 & |1314 & $\left.\right|^{1127}$ & |1127 \\
\hline |101-120 & |1734 & |1601 & 1601 \\
\hline |121-140 & |1442 & |1690 & 1333 \\
\hline |141-160 & |2264 & 1700 & 1577 \\
\hline |161-180 & |2046 & |1882 & |1044 \\
\hline |181-200 & |1980 & |1720 & $\left.\right|^{1742}$ \\
\hline |201-220 & $\left.\right|^{2185}$ & 875 & 1993 \\
\hline |221-240 & |2520 & 1900 & |1581 \\
\hline |241-260 & |1958 & |2092 & |1407 \\
\hline |261-280 & |127 & 106 & |106 \\
\hline |281-300 & $1^{342}$ & $1^{310}$ & |310 \\
\hline |301-320 & |2475 & |1877 & |1407 \\
\hline |321-340 & |2874 & |2336 & 1571 \\
\hline |341-360 & $\left.\right|^{1434}$ & 1070 & 1070 \\
\hline
\end{tabular}




\begin{tabular}{|c|c|c|c|}
\hline $\begin{array}{l}\text { Distr } \\
\text { the } I\end{array}$ & $\begin{array}{l}\text { e commen } \\
\text { and T) }\end{array}$ & IX of & (tab. 3.2) \\
\hline Verses & Codex T & Codices $B / E^{3}$ & Codex C \\
\hline 361-380 & 2498 & 2289 & |1443 \\
\hline $381-400$ & 2473 & 1957 & 1654 \\
\hline |401-420 & |1313 & |935 & |935 \\
\hline |421-440 & |2113 & |2042 & 1099 \\
\hline $441-460$ & 2933 & 2438 & 1272 \\
\hline |461-480 & , 491 & |576 & |576 \\
\hline |481-500 & 1824 & 1482 & |1482 \\
\hline |501-520 & |1662 & |1163 & 960 \\
\hline 521-540 & |2406 & 1859 & |1791 \\
\hline |541-560 & |1684 & 1491 & |1451 \\
\hline |561-580 & |896 & |559 & |559 \\
\hline 581-600 & $\left.\right|^{754}$ & |699 & |699 \\
\hline 601-620 & |1212 & 1716 & 579 \\
\hline |621-640 & |1625 & 1585 & 1316 \\
\hline 641-660 & |1417 & |1041 & 877 \\
\hline 661-680 & 964 ן & 518 & |518 \\
\hline |681-700 & |1022 & 1630 & 534 \\
\hline |701-720 & |195 & 155 & |155 \\
\hline |Total & |61792 & |50574 & |41537 \\
\hline
\end{tabular}

Tab. 3.1 and 3.2: Distribution of the commentary in book IX of the lliad (B/E,$C$, and $T)$

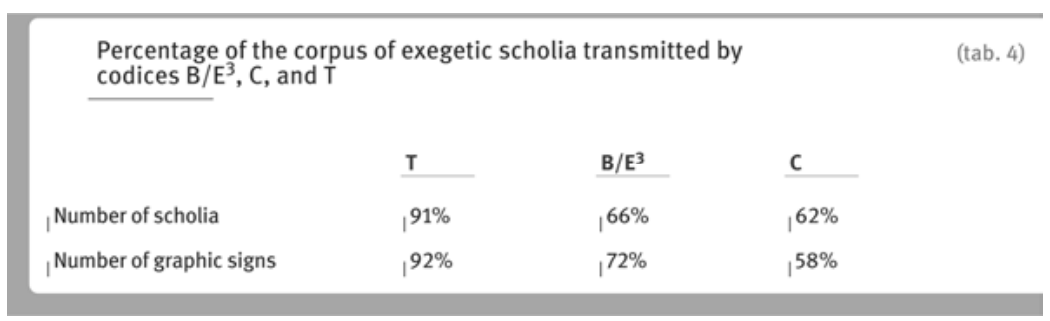

Tab. 4: Percentage of the corpus of exegetic scholia transmitted by codices $B / E^{3}, C$ and $T$ 
This is not the place to discuss the stemmatic relations of the bT family of codices. I shall limit myself to noting that $\mathrm{T}$ certainly descends from a ' $b$ ' witness, from which also the progenitor of the $\mathrm{B}-\mathrm{C}-\mathrm{E}^{3}$ ('c') group derives. The surplus commentary in $\mathrm{T}$ is a result of various factors: a) the addition of a number of 'non exegetic' scholia, taken also from Venetus A, b) the presence of scholia not found in the other three witnesses, and c) the presence of more extensive versions of scholia found also in the other three witnesses. Codex T appears thus as the direct or indirect result of 'selective assembling' of the commentary found in two or more codices. It is probably because of this that the scribe of $\mathrm{T}$ (like the one of Venetus A) adopts a reference system based on lemmas instead of numbers, which allows him greater freedom in the order in which glosses are transcribed (because it avoids the problem of having to organize the glosses on each page according to an ordered sequence of numbers). This system is integrated at a slightly later stage (that is, before the transcription of the interlinear glosses $)^{17}$ with a supplementary system based on symbols. The other witnesses, which follow a homogeneous tradition, adopt instead a numbering system based on two facing pages. I hope to give more details on this aspect in a further contribution. I shall rather focus here on the opposite way in which the scribes of $\mathrm{T}$ and Caddressed the problem of having to transcribe a rather extensive commentary on much smaller pages than the ones used in the twins $\mathrm{B}$ and $\mathrm{E}^{3}$. For reasons that I cannot deal with in detail $^{18}$ (but basically consisting in the adoption of excessively spaced lines and a system of 'dual function' guiding lines ${ }^{19}$ used for both text and scholia), the scribe of $\mathrm{C}$ runs into trouble as soon as the mass of the commentary exceeds 1,100 or 1,200 signs in the Erbse edition. Having underestimated the required space in planning the layout, the scribe finds no solution other than cutting or omitting what he deems the more superfluous parts of the commentary (mostly in long scholia). In fact, there is a clear tendency in the scribe of $\mathrm{C}$ to overestimate the danger of saturating the page and therefore to cut excessively as shown by the fact that in all pages where cuts were performed, empty spaces remained at the end, which led the scribe to reinsert some of the previously excised commentary in the remaining space (Fig. 11). It is also interesting to note that most of the shortened or suppressed scholia refer to the lower third of the page, whereas the majority of the reintegrated ones refer to the top third. Evidently, cuts and omissions were not the result of careful planning but rather of improvised solutions based on rough estimates made when already half-way into the copying of the page.

\footnotetext{
17 The glosses 'jump over' the symbols in the interlinear space.

18 See Maniaci 2006, 233-234 and 257-266.

19 'Two-speed ruling', according to the English terminology developed by J. Peter Gumbert in his unpublished codicological vocabulary (Word for Codices).
} 


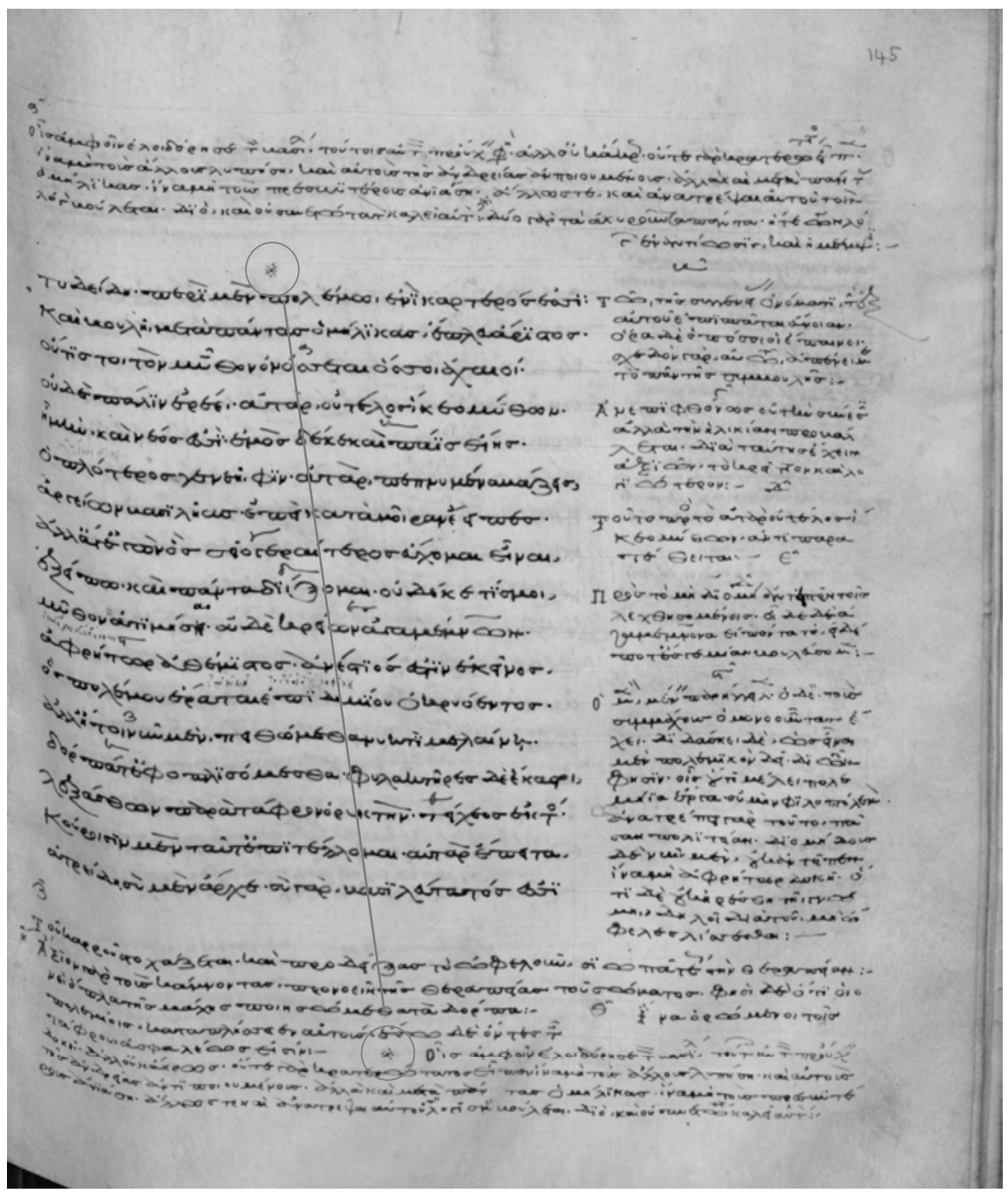

Fig. 11: Florence, Biblioteca Medicea Laurenziana, Cod. Plut. 32, 3 (C), f. 145r. Suppressed and later reintegrated scholia. With permission of the Ministero della Cultura (MiC) 
The choices made by the scribe of Londinensis $\mathrm{T}$ are very different and marked by much greater foresight. Calculations based on the Erbse edition show that $\mathrm{T}$ can carry up to 4,500 graphic signs per page, ${ }^{20}$ an exceptional value considering that in the much bigger codices $\mathrm{B}$ and $\mathrm{E}^{3}$ the maximum number of signs is 3,300 . Codex $\mathrm{T}$, then, contains $25 \%$ more signs in a much smaller space. How did the scribe of $\mathrm{T}$ achieve this exceptional result? First of all, unlike other witnesses, codex $\mathrm{T}$ inserts scholia in the inner margin and interlinear spaces. I have been unable, for the moment, to identify any particular principle governing the distribution of scholia in these two areas other than the obvious fact that interlinear scholia must necessarily be short. In any case, these areas were clearly used as a sort of 'emergency lane', proof of which is the fact that the inner margin contains only $11 \%$ of the scholia against $46 \%$ of the external margin, while interlinear spaces contain about $8 \%$ of the total. About $20 \%$ of the commentary in $\mathrm{T}$ is therefore found in these additional areas. However, even without considering these areas, the average capacity of a page in T remains about the same of a page in the much larger codex B. This is due to the adoption of a proportionally smaller ruling unit and script, once again showing how in framed manuscripts good planning of page layout is essential for an effective arrangement of text and commentary. The negative results in codex $\mathrm{C}$ are reverse proof of the same.

But the evaluation of the codicological quality of the witnesses of scholia bT cannot be limited to their capacity. It is also necessary to judge the extent to which the particular arrangement of text and commentary facilitates the reading of both. One way to evaluate this statistically consists in notionally dividing the page into three horizontal sections and calculating the times a scholium positioned (or beginning) in the upper margin refers to a line of the first section and so on. Codices $\mathrm{T}$ and $\mathrm{B} / \mathrm{E}^{3}$ are generally able to maintain a correct alignment of commentary and text while $\mathrm{C}$ progressively falters and loses ground (Tab. 5).

20 Details will be given in a forthcoming publication [note of the editor: Maniaci 2006]. 


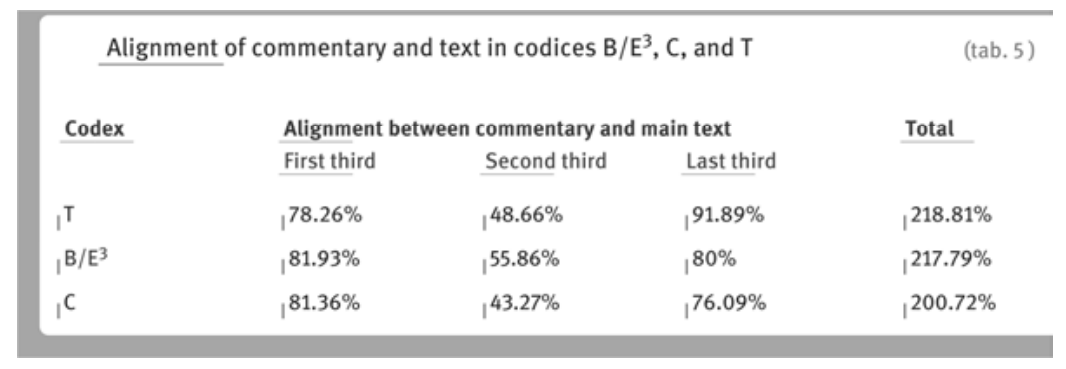

Tab. 5: Alignment of commentary and text in codices $B / E^{3}, C$, and $T$

The T scribe, while facing greater difficulties than his colleagues of the 'twins' B and $\mathrm{E}^{3}$, seems quite capable of containing the commentary within the page and organizing it effectively as far as the 'to and fro' of comment and text is concerned. The skill with which the copyist of $\mathrm{T}$ did his job is confirmed by the absence of any mechanism of compression or expansion of text and handwriting according to the circumstances: unlike other codices, in $\mathrm{T}$ there are no variations in the rate of abbreviations from one area of the page to the other, nor in the lateral compression of the handwriting.

\section{Conclusions}

The systematic analysis of the material features of the manuscript allows us, in a way, to look over the shoulder of the scribe intent on copying the text. In so doing, we realize how, behind the correctness of the text and the regularity of the layout, there lies an invisible and accurate organization of the textual flow over the page and within the individual line, a matter that becomes particularly delicate when the scribe must negotiate at once the flow of the text and the flow of the commentary. From this perspective, the direct analysis of codices is particularly important because it allows us to discover 'between the lines' the hidden rules that regulated a profession much more difficult than commonly believed.

The preservation of the scholia of the Iliad is due for the most part to the ability of the scribes: if Laurentianus $C$ had been the only ungainly survivor, $40 \%$ of the exegetic scholia would have been lost, and little does it matter whether its commentary is globally better or worse than that of the other codices. Textual analysis based on abstract and purposely mechanical comparison of lectiones and loci corrupti is certainly capable of providing us with a plausible framework, a 'skeleton' to which, however, it is still necessary to add the 'body' of the textual 
tradition. If we entrust ourselves blindly to the verdict of a stemma codicum we risk being led to wrong conclusions, losing our way in laborious and unconvincing arguments. In these cases, the detailed analysis of the written page offers an indispensable touchstone capable of definitely settling controversies between hypotheses that, in theory, may be equally possible in the light of what is materially possible and what is not.

\section{References}

Comparetti, Domenico (1901), Homeri llias cum scholiis: Codex Venetus A, Marcianus 454 phototypice editus, Leiden, Lugduni Batavorum: A. W. Sijthoff (Codices graeci et latini photographice depicti, 6).

Dorival, Gilles (1986-95), Les Chaînes éxégetiques sur les Psaumes: Contribution à l'étude d'une forme littéraire, 4 vols, Leuven: Peeters (Spicilegium sacrum Lovaniense, 43-46).

Erbse, Hartmut (ed.) (1969-88), Scholia Graeca in Homeri lliadem (scholia vetera), 7 vols, Berlin: de Gruyter.

Follieri, Enrica (ed.) (1969), Codices graeci Bibliothecae Vaticanae selecti temporum locorumque ordine digesti commentariis et transcriptionibus instructi, Città del Vaticano: apud Bibliothecam Vaticanam (Exempla scripturarum, 4).

Grafton, Anthony (1997), The Footnote: A Curious History, Cambridge, Mass.: Harvard University Press.

*Maniaci, Marilena (2000), 'La struttura delle Bibbie atlantiche', in Maniaci, Marilena / Orofino Giulia (eds), Le Bibbie atlantiche. II Libro delle Scritture tra monumentalità e rappresentazione. Catalogo della mostra, [Milano]: Centro Tibaldi, 47-60.

Maniaci, Marilena (2002a), Costruzione e gestione della pagina nel manoscritto bizantino, Cassino: Università degli studi di Cassino.

Maniaci, Marilena (2002b), “'La serva padrona”: Interazioni fra testo e glossa sulla pagina del manoscritto', in Fera, Vincenzo / Ferraù, Giacomo / Rizzo, Silvia (eds), Talking to the Text: Marginalia from Papyri to Print. Proceedings of a Conference held at Erice, 26 September3 October 1998 as the $12^{\text {th }}$ Course of International School for the Study of Written Records, I-II, Messina: Centro Interdipartimentale di Studi Umanistici, I (Percorsi dei classici, 4-5), 3-35.

Maniaci, Marilena (2006), 'Problemi di mise en page dei manoscritti con commento "a cornice”. L'esempio di alcuni testimoni del'lliade', in Segno e testo, 4: 211-298.

Messeri, Gabriella / Pintaudi, Rosario (2002), 'I lettori dei papiri: dal commento autonomo agli scoli', in Fera, Vincenzo / Ferraù, Giacomo / Rizzo, Silvia (eds), Talking to the Text: Marginalia from Papyri to Print. Proceedings of a Conference held at Erice, 26 September-3 October 1998 as the $12^{\text {th }}$ Course of International School for the Study of Written Records, I-II, Messina: Centro Interdipartimentale di Studi Umanistici, I (Percorsi dei classici, 4-5), 37-57.

Powitz, Gerhardt (1979), 'Textus cum commento', in Codices manuscripti, 5, 80-89 (repr. in Powitz, Gerhardt [ed.] [2005], Handschriften und frühe Drucke: ausgewählte Aufsätze zur mittelalterlichen Buch- und Bibliotheksgeschichte, Frankfurt a. M.: Klostermann [Frankfurter Bibliotheksschriften, 12], 57-81). 